\title{
Globalization and digitalization: The challenges to environmental sociology
}

\author{
Oleg N. Yanitsky \\ Doctor of Philosophy, Professor, Chief Researcher,
} The Federal Center of Theoretical and Applied Sociology of the Russian academy of sciences.

\begin{abstract}
Our world is in a transition to the Fourth scientific and technological revolution (in other terms, to the digital age). This transition generates the deep transformations in all spheres of natural and social life, and the overall trend of them is the turning of our world into very mobile and uncertain entity with permanently changing disposition of competing forces and the transformation of socio-ecological organisms built in the global 'Internet galaxy's network system. An uneven transition of these organisms to the digital world aggravates the studies of these multi-sided global social ecosystems. All these transformations is a challenge to natural, social and technical sciences, the challenge that required a new creative approach to the analysis of such permanently mobile and uncertain socio-ecological structure and to a set of such novelties as virtualization of social life, fundamental changes in a primary eco-structure, new regularities in the biosphere turnover, the hybridization of socio-ecological structures and processes, the metabolic processes and their tempo-rhythms, designing of transboundary socio-ecological structures and many other new phenomena deserving their critical analysis. The article is relied upon the analysis of Russian and foreign research in environmental sociology, on the study of the projects of transboundary ecosystems, and on the personal experience of the author.
\end{abstract}

Keywords: creativity, eco-structures, education, environmental sociology, geopolitics, globalization, hybridization, interdisciplinary research, method, space, tempo-rhythm, time, transition period

\section{INTRODUCTION}

This theme is so vide and diverse that it's not possible to embrace it in the frames of one article. That is why I restrict myself by the only one but rapidly development sphere of modern science, the socio-ecological one in the widest sense of this term. The reason is obvious: it's the realm of intent interest of world scientific community, and of my own researches with which I'm dealing with more than half-a-century.

There are some other reasons of choosing this research area. First, it's a multi-disciplinary, and the further the more its frames continue to widen. Second, it's very dangerous research area because it is now in transition. Every insider or outsider have his/her own opinion about it subject matter, methods of study, dynamics, etc. Third, this science is developing so rapidly so as a particular researchers have no consent because they are studying different phases of this science development. Fourthly, I see myself as the pupil of the fathers of the Chicago Scholl of Human Ecology, but in the run of the past century the theoretical apparatus of environmental sociology had changed very substantially. Fifthly, any science is a living organism and what has been settled yesterday as the constant is now becoming questionable. Sixthly, the requirements to the environmental sociology are coming from many sides, business, political, scientific, journalism, and so on. Seventhly, on the other hand, being simultaneously the insider and the bystander my own understanding of the subject matter of the above discipline has 
permanently changed in the run of my researches. It may be called the races with the evil without the safety net. Eighthly, that is why that sometimes I'd been forced to begin with the scratch. Ninthly, with the coming of the digital era I'd been forced to investigate its requirements. Finally, recently many societies including Russia are in the transition toward this era. It's quite natural that all socio-ecological entities, from the local to global will be substantially transformed. So as I feel myself in the midst of the local-global melting pot of the ideas, opinions, concepts and in the core of permanent dispute.

\section{SOURCES AND THE METHOD}

The sources are as follows: Russian and Anglo-Saxon literature; four international research projects including one of them develops more than 10 years; the study of Russian environmental movement in the 1960-2000s; biographical method using semi-structured longterm interviews and oral histories as well as the study of the biographies of Ch. Darwin, Vl. Vernadsky, Piotr Kapitza and some other outstanding scientists; the works of the fathers of Chicago school of human ecology, and the diaries of some Russian scientists including the retrospective analysis of my own. In the run of the long-tern study of Russian environmental movement I'd focused on the life-spans of those scientists who joined their research work with public activity (Yanitsky, 2008). By and large, I'm becoming convinced that a creativity as indispensable quality of the scientists is rooted not only in his/her research work as such but in the other forms of activity, in particular in construction and making the experiments, during the communication with other people which gave me the very important result: mutual understanding between various specialist as well as with the ordinary people. Thus, it may be stated that the creative scientific study of a researcher-environment relations is the two-ways process.

Besides, the studies of individual biographies of the researchers-turned-civil activists clearly showed a significance of gaining information concerning their childhood including their teenagers' age as well as their cultural and scientific milieu in those times. I agree with those Russian and foreign researchers of the childhood who stated that the child is quickly becoming a social actor and not an object of government of the elderly. It's rather indicative that the information and impressions gained in the childhood then as if disappeared but returned again in the age of 40-60 years old.

All in all, I'd never studied the creative potential of my respondents directly by means of a set of questions in the process of the interviews. I preferred to calculate this potential by means of including observation of their activity. Of course, I've combined these observations with the study of relevant literature i.e. the studies of overt mechanisms of environmental study as an institution (see, for example, Irwin, 2001; Irwin and Wynne, 1996; Jamison, 1996).

\section{Current trends}

A globalization, hybridization, and the speeding up of current socio-ecological processes of any scale are three main challenges to the development of environmental sociology. The ongoing globalization is relied upon the information-communication network structure which embraces the world and stimulates the integrative i.e. metabolic processes between natural, social and technological systems. These processes coupled with a speeding up of the shaping of the integrative i.e. the SBY-systems created an entirely new socio-ecological space i.e. a relative one. The essence of such transformations is the shaping of very small 'compressed' global world in which such parameters of its structure and functions as 'big' and 'small', 'here' and 'there', 'we' and 'they' are becoming very conditional because the space has been converted into the time. 
The hybridization processes are one of the distinguishing characteristics of any evolutionary, socio-economic or geopolitical transformations. But nowadays humanity is entering into a qualitatively new epoch, the hybrid one. The network structures and permanent metabolic processes are the creators of a hybrid and time-compressed structure of our world. Under modern conditions the space of any social activity isn't measured by a 'distance' to overcome but by the social-political impediments which have to be surmounted.

The phenomenon of permanent speeding up of the world dynamics and its nonlinear character are signifying again that the time is becoming the key variable of it, and accordingly the principled conditions of the creative scientific research. In other words, a sustainability of any structural-functional element of our world is only a moment in the processes of permanent structural-functional transformations of its agents. We are living in the constantly changing world - it's the new maxim of modern science.

But it's not all. The matter is that the permanent acceleration of global transformations generates the feedbacks from the side of natural and man-made ecosystems which have their own tempo-rhythms. There are two ways out from this critical situation. One is to slow down the speed of global changes but the global market exists on the basis of the speeding up only. The other is to create the 'islands of sustainability.' But such 'oases' are short-living for the reason of limited stock of resources.

Recently, many societies including Russia are in the transition period towards the digital age or, in my terminology, towards the Fourth scientific and technological revolution. The nature of this period is the combination of the three abovementioned shifts coupled with a restructuration of global-local institutional order. The challenge of this time-span is its uncertainty when the existing social institutes already doesn't work but the new one are only in construction and testing period. As the global political situation showed, all the difficulties of this period are readdressed on the shoulders of the rank-and-file people. Such readdressing leads to the growth of social tension, mass involuntary migrations, ethno-confessional conflicts, etc.

On the global scale, the transition period leads to new contradictions between the US, the EU, China and Russia. The essence of such contradictions is two-fold, a geopolitical domination on the global arena and the strengthening of national defense forces. Finally, this period is marked by the growing use of private military forces such as mobile private small private troops and the hackers' attacks. In turn, it leads to the growth of instability of global social order that risks to be transformed into the Brownian movement of the agents and their networks.

\section{Global context of environmental sociology: A focus on the childhood}

Modern science is living and developing in permanently changing global context. Under the context I mean not only social and political events and transformations of the global scale but human comprehension of his/her place in the social and informational space based on the coming scientific developments and discoveries. Thus, recently a child from his/her early ages is coming into the moving world, and then the races between the changing world and the growing child are beginning. Once again: in such permanently changing world any sustainability is the moment of permanent transformations only. The same conclusion is relates to the 'science-world' relationships. In order to survive the environmental sociology should have the time to reach the changing world.

Let me to start from the scratch. Little children like to construct and de-construct their toys and all other things. It's a very important intellectual instinct that should be never repressed by 
the adults or by other children. By and large the area of their daily contacts is widened. And this process of expansion of a cognitive area is usually continued till the primary school in which the common discipline and rigid day-time are strictly fixed. Any violation of them by the child has to be punished. The process of personal creative development is abruptly stopped. Some children agreed to be subjected to these strict rules of games, and it often means the end of their creativity while others try to surmount these rules by all means. Those who agreed to be governed from the outside are usually didn't lost for any creative work but except a scientific one.

Now I turn to the massive processes. The generation 'Z' born after the 1995 differs both from the generation ' $\mathrm{Y}$ ' and their parents. The qualities of the generation ' $\mathrm{Z}$ ' deserve special attention but some of its features are already clear. This generation thrust to the bloggers and network communities and don't to their parents and to the scientists as well. The representatives of this generation are trust much more to the science fiction and fantasy. It happened that being eight years old I spent much time alone, and the only one window into the world was the science fiction book titled 'Plutoniya' written by Russian scientist academician Vl. Obruchev. Looking back, I think that it had been a stimulus to my becoming a researcher.

As my long-tern observations showed, the child's development as a personality is permanently outstripping the knowledges which he gained in the kindergarten, secondary and the higher schools. Plus the knowledge and experience gained from the computer plays, friends and early inclusion in the 'Internet galaxy.' Therefore, to my mind, the secondary and higher schools are obliged to supply the pupils with basic knowledge concerning the Internet environment. Nevertheless, it's absolutely necessary to explain them that the world in which we live in is developing and unpredictable one. That is there are two interdependent tasks of the teaching and tutorship processes: to think dialectically and to permanently upgrading a discipline of his/her thinking.

Besides, two other sides of making of the future creative researcher in the above research field shouldn't be forgotten. The former is a personal inclination to one or another form of personal activity that maybe changed in the process of education. The latter is an understanding that global world is uncertain and movable milieu so as he or she have to adapt to it. Th. Khun's principle that the sciences' paradigms are changing from time to time is correct (Khun, 1962) but the speed of their replacement is permanently growing.

One more principled point is a law of dispersion of necessary information in various sources made by the US linguist G.K. Zipf $(1932,1949)$. According to it, the only half of necessary information is in scientific journals while the other half is dispersed in an endless quantity of scientific and other publications. That is why the teenagers prefer to use 'secondary' information (from the blogs and social networks) than to look for necessary scientific sources. It's indicative to our times that the teenagers (and nowadays the scientists) are using the information from the blogs and social networks having no idea about the existence of the works of G. Zipf.

The last but is not the least in this section. Being mentally and socially 'computerized', the teenagers and students of the higher schools prefer to use the above non-scientific sources than the articles, synopses and books. That is why the abstracts are very popular but not the long texts. This trend coincides with the other short messages like 'yes', 'no', 'settled', 'deal' and many others. 


\section{Necessary but not sufficient conditions of the creativity}

This section is a cumulative result of my own experience as an environmental sociologist and in particular of my interest in the history of the sciences by means of the making of biographic research of the scientists turned civil and political activists.

First, an initial specialization and the scope of interests are very important. The fathers of Chicago School of human ecology not all had been the researchers. Some of them were the journalists and even muckrakers. Ch. Darwin not immediately had become an evolutionist, Russian and world-known geochemist Vl. Vernadsky had been initially local administrator in the remote province, the writer Anton Chekov had been the doctor, etc. As for me, initially I was a painter then the architect and urban planner, and only gradually I became an environmental sociologist.

Second, a way to the science isn't always direct. Sometimes it's very important to become initially an experiences man and my change the place of work and a narrow specialization had been very fruitful. Even in the exact sciences the way to the science isn't always direct. For some the mathematics is a mission while for the others the mental gymnastics only.

Third, but anyhow, the growing and permanently being in a variety of intellectual environments is of a critical necessity because such presence is positively contagious in many ways. The matter is that every strata of a society has its own social and intellectual milieu. This milieu being semi-closed is reproduced itself in space and time. It's not well-seen from outside but it has its own rules of games, ways of life, circle of close contacts, and so on. If someone is drops out of such circle he/she still remains as its ex-member. The theoretical seminar guided by the Noble laureate acad. Vitaliy Ginsburg at the Institute of physical problems of Russian academy of sciences during 50 years is the best example of such semi-closed scientific community.

A distinguishing feature of a true scientific work is its universal character. Let me give a historical example. The Russian academy of sciences and many other scientific organizations is not only the social institution but a human community as well. The above semi-closed communities had mainly been emerged in three places: at the Houses of scientists, the sanatoriums, and at the summer settlements in the suburbs (i.e. datchas' cooperatives). These settlements had never been the places for the relaxation only. It had been the territories of exchange of scientific information, political news and personal experience. It was the very important territories for mutual intellectual upgrading. The matter is that the scientists, scholars and teachers are needed not only in 'packed' information in the form of the instructions, codes, articles, curriculums and the like but in the processes of free communication. Such contacts coupled with one-to-one communication, and a calm human and natural landscape gives sometimes an extraordinary cumulative effect.

Well organized a daily routine is very important as well. It doesn't mean that in definite time all researchers have to sit behind the table. Some prefer such way of life, the others prefer a walking, still others are permanently walking put the questions to his/her co-workers, etc. Such habit of daily life plays very important role in the unseen processes of generating ideas. And it's one more form of creative environment.

\section{Interdisciplinary research as a promoting environment}

As it has been mentioned earlier, the hybridization processes are one of the distinguishing characteristics of any evolutionary, socio-economic or geopolitical transformations. Due to the 
development of all-embracing and all-penetrating information network structure humanity is now entering into a qualitatively new epoch, the hybrid one.

Such qualitative turn requires new - interdisciplinary - instruments for its analysis and social construction. This qualitative turn requires a new view on basic prerequisites of scientific analysis of current global processes. Modern hybridization processes is a challenge to a scientific creativity and the stimulus to overcome an existing disciplinary barriers. It means that humanity is now entering into a qualitatively new 'environmental' epoch, the hybrid one. Such qualitative turn requires new - interdisciplinary - instruments for its analysis and social construction. More than that, I think that the humanity is a totally hybrid phenomenon because the humans are living in the hybrid milieu created by an all-embracing global networks. Many western sociologists prefer to interpret post-modern societies as a dense network of human interactions. Yes, it's so but insufficient interpretation. Two key processes have to be taken into account. One it's the metabolic processes of various kinds from mutual encouragement to a total mutual annihilation. These processes are the basement of any creative including the life maintenance in all its possible forms. The other is the formation of socio-biotechnical systems (hereafter the SBT-systems) of various scales as a result of numerous metabolic processes (Yanitsky, 2016). The SBT-systems being complex ones exert the feedback impact on the old and newly emerging SBT- systems.

It's one more argument in favor of my thesis on hybridization and chaotic character of the world social order. The challenge to the scientific community of the environmentalists is again two-fold. First, what particular research instruments are needed to grasp adequately that complex and uncertain process? Second, does the interdisciplinary scientific community could offer social and political instruments which will be potent to overcome these chaotic times and to offer a new model of global social order?

To my mind, the interdisciplinary approach is the necessary but insufficient scientific-andpolitical instrument to reach the above goals. Fifty years work of the Club of Rome clearly showed that the initial goal of its efforts as the 'limits to growth' had been insufficient. The 'limits to growth' is a quantitative criterion but we are needed in qualitative transformations as well. Modern capitalism based on information-communication mode of production is in its essence isn't transformable. In order to limit its appetites the humanitarian sciences should come to the forefront. But the humanitarians as the social community only are insufficient. These sciences have to be united with humanistic-oriented political and social forces. Their agenda is to develop more ecologically and humanistic-oriented model of the next phase of global capitalism.

\section{Transcontinental projects as a new object of environmental research}

While the sociologists continue to discuss what is the globalization this process is entered in a qualitatively new phase, a constructivist one. The 'One belt - one road' project is the best example. A transboundary, transcontinental and interdisciplinary character are its main features. It's a true developmental enterprise because such project permanently evolves in space and time. The other its distinguishing feature is its geopolitical character because in the process of it devising, public discussions, reframing and realization the project and it driving forces be it the states or their alliances are constantly obliged to surmount political, social and natural obstacles. In parallel, its initiators and drivers should permanently to explain what it will be and why it has to be constructed. That is the media in the widest sense of the word have to play a 'teaching' i.e. the Enlightenment role and not to serve as the propaganda only. It's the case when a certain global idea and research project have to be far ahead of any constructive works. 
Of course, the 'One belt - one road' is now only one such transboundary, transcontinental and interdisciplinary enterprise of global scale though I'm convinced that it will be followed by many other such initiatives. There are some other such global constructive projects but in all of them the civil organizations took an active part from the very beginning because every step of such projects violates the interests of local people and their national and cultural environment. And some Russian civil organizations, for example the 'Rivers without boundaries', actively participate at all phases of the 'One belt - one road' project creation and implementation. The other examples see in (Shkraduk and Simonov, 2018).

The above project is one more confirmation of my idea of the necessity of making the scientificpublic researches. It's one more confirmation that a collaboration of the state and civil organizations is necessary because the only local civil agents and municipal bodies know well all local secrets of a territory which will be crossed and therefore transformed by such transboundary projects. It means that

R. Robertson (1994) and M. Waters (1995) were absolutely right defining the globalization as a local-global phenomenon.

But the globalization processes doesn't necessarily mean an equity or emancipation of humanity. On the contrary, such transboundary projects may be used as a creeping and hybrid colonization of the countries which it will cross. Surely, it's not a single mean to implement such colonization. Nevertheless, such giant global project is a new area for the environmental sciences and education.

\section{The creative science in an overall institutional environment}

The science is one of the forms of production, mainly of the knowledge one but not only. The science is a recognized driver of social, technological and other forms of human development that is the production of scientific knowledge is potentially profitable. But the science and its products are the Janus like so for some its products may bring health and wellbeing whereas for others these products may make harm, and brings the death. And so the knowledge production has to be regulated and controlled by a man, and that is the problem because for some such control will bring profit while for others creates risks and harms.

Recently the science is a social institution built in the global institutional structure. And so any creative scientific work is situated in the cocoon of numerous bureaucratic codes, instructions, rules, restrictions and protocols which slow down its development and potential profit which she is capable to bring. At the same time to impose new codes and rules on the production of the scientific knowledge is a very profitable business. And this extra-income is going not to the knowledge production developmental environment but mostly to its bureaucratic regulators. That is why many outstanding scientists, researchers and teachers prefer to make their research work, and not to take administrative and political arm-chairs.

Another aspect of the same issue is that the science as a productive force produces not only various kinds of knowledge and technologies. It produces the wealth, the arms and arm systems, social statuses, political weight, working places, text-books, and many other things far from knowledge production as such. Besides, the scientific institution permanently works for its own reproduction and raising it political weight in a society.

Finally, the scientific community is responsible for the maintenance of more or less 'calm' global milieu by means of reducing international tension, the peace strengthening, and ensuring strategic stability (Kokoshin, 2011; Ripple W. at al, 2017). It is very important sphere of interdisciplinary research. 
But in any case, the knowledge production has to be controlled by civil society organizations and by the other forms of public control (public hearings, public expertise, by the analysis implemented by independent, and not by politically-engaged experts, etc.). To my mind, in the sphere of environmental research are gradually developed a certain hybrid which I name the scientific-public researches (Yanitsky, 2006).

\section{The people perception of a public role of science}

The above considerations showed that the science is mainly considered as the social institution and from the viewpoint of its relationships with other social institutions. It has already been stated that the scientific-public researches are one of the instruments of public participation in the research processes and shaping of the living environment. However, what is the science perception by modern individuals? Does in particular, the very term of the 'creative environmental science' is commonly accepted? It's clear that doesn't. Let's consider the issue step by step.

First, a research work, a 'mining' of a new knowledge is an undoubtedly a creative act. Although, the science today is not the creative work of the alones, it's a giant machine of knowledge production and dissemination. Thus, the knowledge production isn't a kind of intellectual work by the definition. This production is the coordinated efforts of many other kinds of creative and routine activity.

Second, as it has been mentioned earlier, the science is in the cocoon of many other institutionalized forms of human activity that may be or may not of a creative character. The social sciences only could said something about the publics' attitudes towards some scientific deeds or discoveries bur it mostly will be a kind of echo of the 'breaking news' translated by the media. Even those who are the insiders of a particular research project couldn't say something definite concerning its process of the results.

Third, as M. Michael argued, 'the ways in which people regard themselves and the value they place upon their scientific knowledge, affects the ways in which they understand the science (Michael, 1996: 107).

Fourth, in all steps 'towards more progressive relationships between knowledge and citizenship, it will be particularly important to consider the emergence and development of new institutional forms which attempt to deal with these issues in a progressive and imaginative fashion (for example, by bringing together both 'indigenous' and 'formalized' knowledges).' More fundamentally the 'social experiments in new science-public interactions often succeed only in re-emphasizing the gulf between scientific institutions - and scientific knowledge - and the general public' (Irwin and Wynne, 1996: 220).

Fifth, the time-span of science perception by the public is also important for the environmental researchers. By this criterion, an overall population of the earth may be roughly divided in the following categories. It's those who are totally ignored any information about the science achievements, this strata is lived in its own space-time rhythm. Then, it's the strata which is interested in the 'breaking news' but only if such news may affect the way of life of this category. After then, it goes the strata of ordinary people who are only the servants of the of new knowledge production institution and therefore are subjected to the time rhythms of a particular knowledge production. The next group consists of those who are considered this institution as a source for their personal enrichment and social status upgrading and so they are interested in the tempo-rhythms of the coming of the investments and not in the results of 
scientific work. And the only one and very small group, the researchers as such are deeply interested and involved in the process of new knowledge production as such.

\section{Socio-ecological entities as a subject matter}

Globalization and digitalization of our life provoked substantial transformations in a more or less stable socio-ecological environment of it. The US researcher D. Stokols carried out a very deep and systemic analysis of already happened and still continued changes in this research area. He stated that the 'Social ecology's mission is not only descriptive and explanatory but also transformative and moral. If we are truly committed to human and biospheric survival, we must put political and ideological biases aside and infuse ecological precepts into our daily activities, built environments, and governance systems' (Stokols, 2018: 354).

In this section I'd summarize my own considerations and research results related to the newly emerging issues waiting for their creative analysis in this very complex area of interdisciplinary science.

First, our planet represents a structural-functional system which consists of at least of the following structural elements: space structures and processes, biosphere turnover (partly already violated by man activity), networks and flows, nodes at their crossroads, and natural and social ecosystems. These nodes are simultaneously playing the role of drivers of scientific and technological progress and potentially risky places.

Second, the local-global structures of the socio-ecological environment are still remained but they are continued to become more and more uncertain and mobile. To my mind, it's the result of growing mobility of the global SBT-systems. It is logically understandable: if the global whole is becoming mobile, its smaller and subaltern parts are developing in the same way.

Third, the environment of human activity is expanding as well embracing now all three sphere of human activity: underground (the lithosphere and mantle), the surface of earth as such and the space. The further the more the space is making habitable by man. But such mastering often has short-lived and therefore hasn't regular character.

Fourthly, at the same time one could observe the reverse trend: in time the living environment is devastated, partly due to the abrupt climatic fluctuations, partly as a result of destructive human activity in relation to the existing natural and social ecosystems.

Fifthly, as a sociologist, I am deeply concerned with the distraction of a primary eco-structure and first of all of a family and its immediate milieu (Yanitsky, 2012) by the growing overall mobility, forced gender equity, permanent looking for a job as well as by the growing overall uncertainty of global human population as a whole. Recently the typical primary eco-structure is an individual armed with an I-phone.

Sixthly, this uncertainty is enhanced by unstable and sometimes chaotic international relations, ethno-confessional conflicts, resource and hybrid wars and natural and man-made disasters. The global uncertainty is enhanced by the abovementioned transition period when some countries are going far ahead, others stagnate, and still others disappear from the geopolitical arena as social actors.

Seventhly, the global situation aggravates by humans existence in two spaces, material and virtual ones. This double existence has very different structural and functional characteristics, the tempo-rhythms of their changes and many other peculiarities. 
Eighthly, the 'One belt - one road' as the transboundary project is the example of a new environmental structure organized and developed in accordance with the march of the project development. The designers of it consider it as a developmental eco-structure. But one has to take into account the feedbacks that could came from various parts of the world. As a result, we are getting a new 'dispersed' global environmental structure which deserves special attention of interdisciplinary analytics.

Ninthly, if one step down to a mega-cities level as the largest nodes of global socio-ecological structure he'll see a new form of a spatial segregation: the isolated 'islands' of the transnationals' headquarters, closed and self-contained communities of the rich and also closed communities of the poor and jobless. It turned out that the mega-cities are transforming into numerous cells built in a digital global whole? But what is in-between them? Is it an empty social space or socially devastated areas?

Tenthly, generalizing the previous hypothesis we are occurring in the environment of a myriad closed but changing socio-ecological structures interconnected by permanently switching global network structures only. Is it that the 'brave new world' which humanity had been waiting for centuries? Or we are moving towards totally disorganized social world subjected to the laws of the Brownian movement? Or more roughly: is such movable, uncertain and conflicting world is a new moral norm?

\section{CONCLUSION}

Environmental sociology in the digital age is a new and very important field of interdisciplinary researchers. Keeping in mind the movable and uncertain character of the world in which we live in, it's a very difficult research area required joint efforts of the likeminded scientists and experienced people in this research area.

The time is a critical feature of ongoing transformations and an important criterion for the estimation of the races between the permanent global transformations and their comprehension by the above complex research teams.

The moral foundations of the mobile and uncertain global social environment are important but insufficient. These moral foundations are usually the result of the reconciliation of competing interests. The understanding of how to reconcile these opposing interests of global and local stakeholders for the deficit resources and geopolitical domination and simultaneously diminishing the violation of the biosphere turnover is one of the primary tasks of creative environmental science. This global issue cannot be resolved without transformation of existing social order that is of the changes in the mode of production and consumption.

The creative environmental science today is the science capable to offer the new rules of games and use them to renovate the global social order. It means that this science has to be ahead of ongoing transformations. One of the instruments for such outstripping them could be the information-communication technologies assisting to the scientists in the monitoring of ongoing global changes, quickly processing the results of monitoring and assisting to the tandem of the scientists and politicians to take right decisions in time. But for doing this the science as the social institution should have the allies, and first of all among like-minders and allies in all strata of the existing civil society.

The creation of transcontinental and transboundary socio-ecological systems burdened with local-global metabolic processes is one more new challenge for the global environmental 
community, and therefore the new creative research field for environmental sociology. It's the challenge but as many scientists stated, the bad result is the best teacher.

The advancing of public understanding of new knowledge production depends upon of a willingness of the state and civil society bodies to discuss the changing character of this production under conditions of the digital age. But the key methodological principle remains the same: follow the actor that is a collective process of new knowledge production. It's quite natural that at every qualitative leap of its subject matter, for example from globalization to a universe at large the social structure of new environmental knowledge production and its tempo-rhythms will change again.

\section{References}

Irwin A. 2001. Sociology and Environment. A Critical Introduction to Society, Nature and Knowledge. Malden, MA: Polity. 210 pp.

Irwin A. and Wynne B., eds. 1996. Misunderstanding Science? The Public Reconstruction of Science and Technology. Cambridge: Cambridge University Press. 232 p.

Jamison A. 1996. The Shaping of the Global Environmental Agenda: The Role of Non-governmental Organizations, in: Lash S., B. Szerszinski and B. Wynne. Risk, Environment and Modernity. London: Sage, pp. 224-45.

Kokoshin A. 2011. Ensuring Strategic Stability in the Past and Present: Theoretical and Applied Questions. Moscow: SIU HSE.

Khun T. 1962. The Structure of Scientific Revolutions. Chicago: The Chicago University Press (First Ed.).

Ripple W. at al. 2017. The World Scientists Warning to Humanity: A Second Notice. Bioscience, Vol. 67, Issue 2, December 2017: 1026-1028. https://doi.org/10.1093/biosci/bix125

Michaele M. 1996. Ignoring Science: Discourses of ignorance in the public understanding of science, in: Irwin A. and Wynne B., eds. 1996. Misunderstanding Science? The Public Reconstruction of Science and Technology. Cambridge: Cambridge University Press, pp. 107-125.

Robertson R. 1994. Globalization. Social Theory and Global Culture. London: SAGE Publications. 211 pp.

Shkraduk I. and Simonov E. 2018. Crossroads of the World Energy and China's Global Energy Interconnections. Technical Report. 45 pp. DOI: 10.13140/RG.2.2.21452.10855

Stokols D. 2018. Social Ecology in the Digital Age. Solving Complex Problems in a Globalized World. Univ. of California: Academic Press. 399 pp.

Waters M. 1995. Globalization. Lnd. \& N.Y.: Routledge. 185 pp.

Yanitsky O. 2005. Dialogue between Science and Society. Social Sciences. A Quarterly Journal of the Russian Acad. of Sciences Vol. 36, No 2, Pp.78-90.

Yanitsky 0. 2006. A Production of socio-ecological knowledge. Political and cultural issues. Social sciences and contemporaneity. No 6: 138-147 (In Russ.).

Yanitsky O., ed. 2008. Modernization in Russia: Challenges to Research and Education. Institute of Sociology: Moscow.

Yanitsky 0. 2008a. Training + Research (First Experience with Tutorship). In: Yanitsky O., ed. Modernization in Russia: Challenges to Research and Education. Institute of Sociology: Moscow: 3-12.

Yanitsky 0. 2009. The Shift of Environmental Debates in Russia, Current Sociology 57 (6): 747-766.

Yanitsky 0. 2010. Russian Environmentalism. The Yanitsky Reader. Moscow: TAUS.

Yanitsky, O. 2012. A Primary Eco-Structure: The Concept and its Testing. Social Analysis, Vo.2 No 2: 7-24.

Yanitsky 0. 2016. Sotsiobiotechnical systems: A new view on man-nature relations. Sotsiologicheskaya nauka i sotsial'naya praktika, Vol. 4, no 3: 5-22 (in Russ.).

Available at: http://manuscript.sciknow.org/uploads/ojssr/pub/ojssr 140963345.pdf

Zipf G. 1932. Selected Studies of the Principle of Relative Frequency in Language. Cambridge (Mass.).

Zipf G. 1949. Human Behavior and the Principle of the Least Effort. Addison-Wesley. 